\title{
Direct oral anticoagulants in real practice: which doses for which patients. Limitations and bleeding risk compared to vitamin $K$ antagonists
}

\author{
Giancarlo Landini, ${ }^{1}$ Luca Masotti ${ }^{2}$ \\ ${ }^{1}$ UO Medicina Interna, Ospedale Santa Maria Nuova Firenze; ${ }^{2}$ UO Medicina Interna, Ospedale di Cecina (LI), Italy
}

\begin{abstract}
The new oral direct anticoagulants (DOACs) could represent a new frontier for management of thromboembolic diseases. However, the new drugs have limitations that need to be considered. Despite the fact that their efficacy and safety profile are at least not inferior to comparators, bleeding risk represents the most feared complication, as for all the antithrombotic drugs. Bleeding risk increases with conditions that interfere with pharmacokinetics, in addition to the risk strictly linked to patients or their co-morbidities. Since all DOACs are excreted from kidneys (even though at different percentages according to the different molecules), renal impairment represents one of the leading causes of DOACs accumulation and bleeding risk. Moderate renal failure is the main condition in which dose adjustment of DOACs could be required, while severe renal impairment represents an absolute contraindication for their use. Renal function must, therefore, be carefully monitored before prescription and during assumption. The older population is at higher bleeding risk, and dose adjustment of DOACs could be required. Although to a lesser degree than oral anticoagulant vitamin K antagonists, DOACs can have drug interactions, especially with P-glycoprotein and cytochrome P3A4 inducers or inhibitors, and these interactions must be taken into account in real practice to avoid accumulation or under dosage. The concomitant use of other drugs, especially antithrombotics, may expose the patients to bleeding risk by reducing the hemostatic properties.
\end{abstract}

\section{Introduction}

The results of the phase III randomized clinical trials (RCTs) on new oral anticoagulants, the direct oral anticoagulants (DOACs), seem to open up new frontiers in the prevention and treatment of venous thromboembolism (VTE), in cardioembolic prevention of non-valvular atrial fibrillation (NVAF) and, only for rivaroxaban, in the acute treatment of coronary syndrome (ACS). ${ }^{1-7}$

Correspondence: Giancarlo Landini, UO Medicina Interna, Ospedale Santa Maria Nuova, Firenze, Italy.

E-mail: giancarlo.landini@asf.toscana.it

Key words: dabigatran, rivaroxaban, apixaban, renal failure, creatinine clearance, dosage, contraindication, bleedings.

Received for publication: 24 April 2013.

Revision received: 4 July 2013.

Accepted for publication: 29 August 2013.

This work is licensed under a Creative Commons Attribution NonCommercial 3.0 License (CC BY-NC 3.0).

(C) Copyright G. Landini and L. Masotti, 2013

Licensee PAGEPress, Italy

Italian Journal of Medicine 2013; 7(s8):41-47

doi:10.4081/itjm.2013.s8.41
When compared with indirect oral anticoagulants, the vitamin $\mathrm{K}$ antagonists (VKAs), the DOACs have been demonstrated to be at least not inferior in efficacy and safety. ${ }^{2-5,8,9}$ Furthermore for many safety end points, the DOACs have been demonstrated to be significantly superior in reducing bleeding events. What is of great interest, and deserves practical consideration when compared with VKAs, is the fact that the DOACs have been shown to reduce the incidence of intracranial bleedings, the most feared complication of the anticoagulant drugs and of all the antithrombotic therapies. ${ }^{2-5,8,9}$ Table 1 summarizes the main results on safety profile of DOACs compared with warfarin in the phase III RCTs.

Post-marketing reports confirm the good safety profile of DOACs. Very recently, in fact, a Food and Drug Administration (FDA) survey has shown that dabigatran used for cardioembolic prophylaxis of NVAF is associated to a significantly lower incidence of intracranial bleedings in real life compared with warfarin. ${ }^{10}$ Moreover, the same survey has demonstrated that dabigatran is also safer over warfarin in gastrointestinal bleedings, the only safety end point on which the RE-LY study had failed to demonstrate noninferiority of the new drug. ${ }^{10}$ Another report of clinical practice in Denmark demonstrates that the rate of major bleedings with both doses of dabigatran (110 $\mathrm{mg}$ bid or $150 \mathrm{mg} \mathrm{bid}$ ) is similar to that of warfarin, 
but the overall mortality and intracranial bleeding rates are significantly lower for both doses of dabigatran over warfarin. ${ }^{11}$ Furthermore, both rivaroxaban and dabigatran have been shown to be associated with a favorable safety profile as the main orthopedic prophylaxis in phase IV studies. ${ }^{12-16}$

The availability of DOACs has inevitable repercussions on the practical management of these diseases, but many real life situations in patients suitable for treatment with DOACs remain challenging. This is because of the unresolved question as to how to interpret pivotal clinical trials in which the numbers of some selected populations that are not negligible in terms of prevalence in the real world were actually poorly represented or were excluded, or due to the lack of phase IV post-marketing clinical studies.

Therefore, the aim of this paper is to present the available recommendations for the use of DOACs in clinical practice, with particular attention to dose management and its adjustment in selected clinical conditions, such as advanced age, renal and liver diseases, extreme body weights, and concomitant use of drugs other than DOACs.

\section{Standard doses of DOACs}

Table 2 summarizes the standard doses of DOACs used in phase III RCTs. The standard doses of dabigatran recommended for clinical practice are 150 or $220 \mathrm{mg}$ once a day (od) in VTE prevention in major orthopedic surgery, $110 \mathrm{mg}$ or $150 \mathrm{mg}$ twice daily (bid) for cardioembolic prevention in NVAF. ${ }^{17} \mathrm{Con}$ sidering this latter setting, the RE-LY study tested two doses of dabigatran versus warfarin. ${ }^{2}$ Briefly, the re- sults of the RE-LY study showed that higher dose of dabigatran (150 mg bid) was associated to superiority of the new drug over warfarin under the efficacy profile and non-inferiority under the safety profile, while lower dose (110 mg bid) was associated to non-inferiority under the efficacy profile, while it showed superiority under the safety profile., ${ }^{2,3}$ For both dosages, the RE-LY study, as mentioned above, showed superiority of warfarin over dabigatran in gastrointestinal bleedings. ${ }^{2,3}$ The results of the RE-LY study seem to suggest a preferance for higher doses of dabigatran in patients at higher thromboembolic risk assessed by using the $\mathrm{CHA}_{2} \mathrm{DS}_{2}$-VASC score, while lower doses of dabigatran should be preferred in patients with higher bleeding risk. It has been suggested to use the HAS-BLED score for the estimation of bleeding risk, It has been suggested to use the HAS-BLED score to estimate bleeding risk, but there could be concerns in naïve patients who have never been treated with VKAs, since HAS-BLED could underestimate bleeding risk in this subgroup of patients due to the fact that the score assigns one point to labile (L) international normalized ratio (INR). ${ }^{18}$ However, there is general agreement on reserving the higher dose of dabigatran for patients with CHADS-VASC score of 2 or over and HAS-BLED score of 2 or under, and the lower dose of dabigatran in patients with HAS-BLED score of 3 or over. ${ }^{18-20}$

In the setting of VTE treatment, the standard dose tested in the RE-COVER study was $150 \mathrm{mg}$ bid, but, up to now, the drug has not yet been considered for this purpose. ${ }^{21}$ The standard doses of rivaroxaban already recommended for clinical use are $10 \mathrm{mg}$ od in VTE prevention and $20 \mathrm{mg}$ od in NVAF. ${ }^{22,23}$ In the setting of acute VTE treatment, rivaroxaban is now ap-

Table 1. Bleeding risk in phase III studies comparing DOACs with warfarin.

\begin{tabular}{|c|c|c|c|c|c|c|}
\hline \multirow[t]{2}{*}{ Study } & \multicolumn{2}{|c|}{ Major bleedings } & \multicolumn{2}{|c|}{$\begin{array}{l}\text { DOACs } v s \text { warfarin } \\
\text { Intracranial bleedings }\end{array}$} & \multicolumn{2}{|c|}{ Total bleedings } \\
\hline & Risk & $\begin{array}{l}\text { Relative risk } \\
\text { reduction }\end{array}$ & Risk & $\begin{array}{l}\text { Relative risk } \\
\text { reduction }\end{array}$ & Risk & $\begin{array}{l}\text { Relative risk } \\
\text { reduction }\end{array}$ \\
\hline RE-LY & & & & & & \\
\hline $110 \mathrm{mg}$ & $0.80(0.70-0.93)^{*}$ & $-20 \%(-30 /-7 \%)$ & $0.31(0.20-0.47)^{*}$ & $-69 \%(-80 /-57 \%)$ & $0.78(0.74-0.83)^{*}$ & $-22 \%(-26 /-17 \%)$ \\
\hline $150 \mathrm{mg}$ & $0.93(0.81-1.07)$ & $-7 \%(-19 /+7 \%)$ & $0.40(0.27-0.60)^{*}$ & $-60 \%(-73 /-40 \%)$ & $0.91(0.86-0.97)^{*}$ & $-9 \%(-14 /-3 \%)$ \\
\hline ROCKET-AF & $1.04(0.90-1.20)$ & $+4 \%(-10 /+20 \%)$ & $0.67(0.47-0.93)^{*}$ & $-33 \%(-53 /+7 \%)$ & $\mathrm{nr}$ & \\
\hline ARISTOTLE & $0.69(0.60-0.80)^{*}$ & $-31 \%(-40 /-20 \%)$ & $0.42(0.30-0.58)^{*}$ & $-58 \%(-70 /-42 \%)$ & $0.71(0.68-0.75)^{*}$ & $-29 \%(-32 /-25 \%)$ \\
\hline RE-COVER & $0.82(0.45-1.48)$ & $-18 \%(-65 /+48 \%)$ & $\mathrm{nr}$ & 1 & $0.71(0.59-0.85)^{*}$ & $-29 \%(-41 /-15 \%)$ \\
\hline RE-COVER II & $0.69(0.36-1.33)$ & $-31 \%(-64 /+33 \%)$ & $\mathrm{nr}$ & l & $0.71(0.60-0.84)^{*}$ & $-29 \%(-40 /-16 \%)$ \\
\hline RE-MEDY & $0.52(0.27-1.02)$ & $-48 \%(-73 /+2 \%)$ & $\mathrm{nr}$ & / & $0.71(0.61-0.83)^{*}$ & $-29 \%(-39 /-17 \%)$ \\
\hline EINSTEIN DVT & $0.65(0.33-1.30)$ & $-35 \%(-67 /+30 \%)$ & $\mathrm{nr}$ & 1 & $\mathrm{nr}$ & / \\
\hline EINSTEIN PE & $0.49(0.31-0.79)^{*}$ & $-51 \%(-69 /-21 \%)$ & $\mathrm{nr}$ & l & $\mathrm{nr}$ & / \\
\hline AMPLIFY & $0.31(0.17-0.55)^{*}$ & $-69 \%(-83 /-45 \%)$ & $\mathrm{nr}$ & l & $0.44(0.36-0.55)$ & $-56 \%(-64 /-45 \%)$ \\
\hline
\end{tabular}

DOACs, direct oral anticoagulants; nr, not reported. *Significant. 
proved at a dosage of $15 \mathrm{mg}$ bid for three weeks from the acute event followed by $20 \mathrm{mg}$ od for long-term and extended treatment. ${ }^{8,9,22,23}$ Although currently under consideration, the use of rivaroxaban in the setting of ACS has not yet been approved. In this context, the doses tested in the phase III study were $2.5 \mathrm{mg}$ or $5 \mathrm{mg} \mathrm{bid}{ }^{7}$ Finally, the standard doses of apixaban are respectively $2.5 \mathrm{mg}$ bid in VTE prevention in orthopedic surgery and $5 \mathrm{mg}$ bid in NVAF. ${ }^{24}$ The dose of apixaban tested for acute VTE treatment is $10 \mathrm{mg}$ bid for one week followed by $5 \mathrm{mg}$ bid. ${ }^{25}$

\section{When to change the dose?}

\section{Elderly patients}

Despite the fact that, in real life, elderly patients represent the biggest category of patients at risk or affected by VTE, NVAF and ACS, only a fairly low percentage of these patients are included in phase III RCTs on DOACs.

In the context of VTE prevention in orthopedic surgery, the dose of dabigatran should be reduced to $150 \mathrm{mg}$ od in patients over 75 years of age. ${ }^{26}$

Rivaroxaban and apixaban do not require dose adjustment in the prophylaxis and treatment of VTE in patients over 75 years of age.$^{22-24}$ For this subgroup of patients, experts recommend considering a dose reduction (15 mg/od instead of $20 \mathrm{mg} / \mathrm{od}$ ) of rivaroxaban in long-term and extended VTE treatment if bleeding risk exceeds the risk of VTE recurrence. ${ }^{23}$

In the setting of NVAF in patients over 80 years of age, practical recommendations arising from the analysis of phase III studies, suggest choosing the lower dose of dabigatran $(110 \mathrm{mg}$ bid $) .{ }^{17}$ In patients over 75 years of age, dabigatran should be used at lower doses only in those with high bleeding risk (75). In fact, the subgroup analysis of elderly patients of the RE-LY study showed that with the higher dose of dabigatran $(150 \mathrm{mg}$ bid) there was a trend towards higher risk of extracranial bleedings over warfarin in patients over 75 years of age. ${ }^{27}$
No dose reductions are recommended for rivaroxaban in very old patients, although patients at higher bleeding risk should be managed with caution. ${ }^{22,23}$ Apixaban should be reduced to a dose of $2.5 \mathrm{mg}$ bid in patients over 80 years of age when they have at the same time at least one of the following characteristics: weight under $60 \mathrm{~kg}$ or creatinine levels $1.5 \mathrm{mg} / \mathrm{dL}$ or over. ${ }^{5,25}$

\section{Extreme weights}

The lower dose of dabigatran, $110 \mathrm{mg}$ bid, should be used in patients with NVAF and body weight under $60 \mathrm{~kg} .{ }^{17}$ Dose adjustment of rivaroxaban is not recommended for patients at the lowest end of the weight range. ${ }^{22,23}$

Dose adjustment of apixaban is required if low body weight $(<60 \mathrm{~kg})$ is contemporary to creatinine levels of $1.5 \mathrm{mg} / \mathrm{dL}$ or over or advanced age $(>80$ years). ${ }^{25}$

No dose adjustment is required for obese patients with body weight over $100 \mathrm{~kg}{ }^{17,22,23,25}$

\section{Organ failure}

Renal failure: knowledge of pharmacokinetics is fundamental for the practical management of DOACs. Kidneys play an important role in DOACs elimination, but this role differs according to the different DOACs. While $80 \%$ of the dose of dabigatran is eliminated from the kidneys, only one-third of active rivaroxaban and $25 \%$ of apixaban are excreted through the urinary system. ${ }^{28}$ Therefore, the half-life of DOACs is prolonged from renal impairment and in this context there could be drug accumulation.

Dabigatran is absolutely contraindicated in patients with severe renal failure (creatinine clearance $(\mathrm{CrCl})<30 \mathrm{~mL} / \mathrm{min}){ }^{17,28}$ As mentioned above, lower dose of dabigatran (110 mg bid) should be used in patients with moderate renal failure $(\mathrm{CrCl} 30-49$ $\mathrm{mL} / \mathrm{min}$ ) when they are over 75 years of age and at high bleeding risk. ${ }^{17}$ Otherwise, dabigatran could be used at a dose of $150 \mathrm{mg}$ bid also in patients with moderate renal failure. ${ }^{17}$

Table 2. Standard doses of DOACs in phase III randomized clinical trials.

\begin{tabular}{|c|c|c|c|}
\hline & DABIGATRAN & RIVAROXABAN & APIXABAN \\
\hline \multicolumn{4}{|l|}{ VTE } \\
\hline Prevention in major orthopedic surgery & $150 \mathrm{mg}$ od or $220 \mathrm{mg}$ od & $10 \mathrm{mg}$ od & $2.5 \mathrm{mg}$ bid \\
\hline Treatment & $150 \mathrm{mg}$ bid & $\begin{array}{l}15 \mathrm{mg} \text { bid for three weeks } \\
\text { followed by } 20 \mathrm{mg} \text { od }\end{array}$ & $\begin{array}{l}10 \mathrm{mg} \text { bid for one week } \\
\text { followed by } 5 \mathrm{mg} \text { bid }\end{array}$ \\
\hline Prevention in the medical patient & l & $10 \mathrm{mg}$ od & $2.5 \mathrm{bid}$ \\
\hline NVAF & $110 \mathrm{mg}$ bid or $220 \mathrm{mg}$ bid & $20 \mathrm{mg}$ od & $5 \mathrm{mg}$ bid \\
\hline ACS & I & $2.5 \mathrm{mg}$ or $5 \mathrm{mg}$ bid & $5 \mathrm{mg}$ bid \\
\hline
\end{tabular}

VTE, venous thromboembolism; NVAF, non-valvular atrial fibrillation; ACS, acute coronary syndrome; od, once daily; bid, twice daily. 
Despite the fact that, in phase III RCTs on NVAF with rivaroxaban (ROCKET-AF) and apixaban (ARISTOTLE), patients with severe renal impairment were excluded and, therefore, not tested, the practical recommendations about these drugs, based on preclinical pharmacokinetic studies, suggest using rivaroxaban and apixaban also in subjects with $\mathrm{CrCl}$ between 30 and $15 \mathrm{~mL} / \mathrm{min}$, even if at lower doses. $^{22,23,25}$ Therefore, rivaroxaban and apixaban should be used at standard dose in patients with $\mathrm{CrCl}$ over $50 \mathrm{~mL} / \mathrm{min}$, while there should be a dose adjustment in patients with $\mathrm{CrCl}$ between 49 and 15 $\mathrm{mL} / \mathrm{min}, 15 \mathrm{mg}$ od and $2.5 \mathrm{mg}$ bid. $^{22,23}$ It should be noted that dose adjustment of apixaban is indicated if creatinine levels are $1.5 \mathrm{mg} / \mathrm{dL}$ or over associated with advanced age ( $>80$ years) or low body weight $(<60$ $\mathrm{kg}){ }^{5,25} \mathrm{~A}$ subgroup analysis of patients enrolled in the ROCKET-AF study showed that the dose of $15 \mathrm{mg}$ od in approximately 1500 patients with moderate renal failure is consistent with the dose of $20 \mathrm{mg}$ od used in patients with $\mathrm{CrCl}$ over $50 \mathrm{~mL} / \mathrm{min}$ in terms of efficacy and safety over adjusted doses of warfarin..$^{29}$

Similar considerations should be made in the context of VTE where dabigatran remains contraindicated in patients with severe renal failure $(\mathrm{CrCl}<30$ $\mathrm{mL} / \mathrm{min}$ ), while rivaroxaban and apixaban should not be used for $\mathrm{CrCl}$ values below $15 \mathrm{~mL} / \mathrm{min} \cdot{ }^{22,23,25,26} \mathrm{~A}$ lower dose of dabigatran $(150 \mathrm{mg}$ od $)$ is recommended in patients with moderate renal impairment in the context of VTE prophylaxis in orthopedic surgery while $110 \mathrm{mg}$ bid should be reserved for VTE treatment. ${ }^{26}$ Dose adjustment for moderate renal failure is not recommended for rivaroxaban in orthopedic VTE prophylaxis nor in the acute phase of VTE treatment. ${ }^{22,23}$ In the chronic phase of VTE treatment, a reduced dose of rivaroxaban should be considered in those patients with moderate renal failure ( $15 \mathrm{mg}$ od) only if the bleeding risk exceeds the risk of thromboembolic recurrence. $^{22}$ Table 3 summarizes the recommended doses in patients with renal failure. The respect of dose adjustment of DOACs according to renal function is of utmost importance. In fact, first reports on bleedings associated with dabigatran demonstrated that the majority of bleedings occurred in patients with renal failure in whom there had been no dose adjustment in moderate renal failure or in whom the drug was not discontinued in the presence of severe renal failure. ${ }^{30}$

Liver diseases: all DOACs are contraindicated in patients with class C Child-Pugh cirrhosis or when levels of transaminases are two times that of baseline. ${ }^{17,22-24,26}$ Therefore, the periodic evaluation of $\mathrm{CrCl}$ and liver function is of the utmost importance in patients on DOACs. Such evaluation, together with blood count and coagulation parameters, should also be carried out at the beginning of treatment in order to exclude those patients in whom DOACs could be

Table 3. Recommended doses for DOACs in renal failure.

\begin{tabular}{|c|c|c|c|c|}
\hline & $\begin{array}{l}\text { Mild renal impairment } \\
\text { CrCl } \\
50-80 \mathrm{~mL} / \mathrm{min}\end{array}$ & $\begin{array}{l}\text { Moderate renal impairment } \\
\text { CrCl } \\
49-30 \mathrm{~mL} / \mathrm{min}\end{array}$ & $\begin{array}{l}\text { Severe renal impairment } \\
\mathrm{CrCl} \\
29-15 \mathrm{~mL} / \mathrm{min}\end{array}$ & $\begin{array}{c}\text { End-stage renaI impairment } \\
<15 \mathrm{~mL} / \mathrm{min}\end{array}$ \\
\hline \multicolumn{5}{|c|}{ Venous thromboembolism prophylaxis } \\
\hline Dabigatran & $\begin{array}{l}150 \mathrm{mg} \text { od } \\
220 \mathrm{mg} \mathrm{od}\end{array}$ & $\begin{array}{l}150 \mathrm{mg} \text { od } \\
220 \mathrm{mg} \text { od }\end{array}$ & Contraindicated & Contraindicated \\
\hline Rivaroxaban & $10 \mathrm{mg}$ od & $10 \mathrm{mg}$ od & $10 \mathrm{mg}$ bid & Contraindicated \\
\hline Apixaban & $2.5 \times 2$ bid & $2.5 \times 2$ bid & $2.5 \times 2$ bid & Contraindicated \\
\hline \multicolumn{5}{|c|}{ Venous thromboembolism treatment } \\
\hline Dabigatran & $150 \mathrm{mg}$ bid & $150 \mathrm{mg}$ bid & Contraindicated & Contraindicated \\
\hline Rivaroxaban & $\begin{array}{l}15 \mathrm{mg} \times 2 \text { bid for three weeks } \\
\text { followed by } 20 \mathrm{mg} \text { bid }\end{array}$ & $\begin{array}{l}15 \mathrm{mg} \times 2 \text { bid for three weeks } \\
\text { followed by } 20 \mathrm{mg} \text { bid }\end{array}$ & $\begin{array}{l}15 \mathrm{mg} \times 2 \text { bid for three weeks } \\
\text { followed by } 20 \mathrm{mg} \text { bid }\end{array}$ & Contraindicated \\
\hline Apixaban & $\begin{array}{l}10 \mathrm{mg} \times 2 \text { bid for one week } \\
\text { followed by } 5 \mathrm{mg} \times \text { bid }\end{array}$ & $\begin{array}{l}10 \mathrm{mg} \times 2 \text { bid for one week } \\
\text { followed by } 5 \mathrm{mg} \times \text { bid }\end{array}$ & $\begin{array}{l}10 \mathrm{mg} \times 2 \text { bid for one week } \\
\text { followed by } 5 \mathrm{mg} \times \text { bid }\end{array}$ & Contraindicated \\
\hline \multicolumn{5}{|c|}{ Non-valvular atrial fibrillation } \\
\hline Dabigatran & $150 \mathrm{mg}$ or $110 \mathrm{mg} \times 2 \mathrm{bid}$ & $150 \mathrm{mg}$ or $110 \mathrm{mg} \times 2 \mathrm{bid}$ & Contraindicated & Contraindicated \\
\hline Rivaroxaban & $20 \mathrm{mg}$ od & $15 \mathrm{mg}$ od & $15 \mathrm{mg}$ od & Contraindicated \\
\hline Apixaban & $5 \mathrm{mg}$ bid & $\begin{array}{l}2.5 \mathrm{mg} \text { bid } \\
\text { If renal impairment is } \\
\text { associated to age }>80 \text { years } \\
\text { or body weight }<60 \mathrm{~kg}\end{array}$ & $\begin{array}{l}2.5 \mathrm{mg} \text { bid } \\
\text { If renal impairment is } \\
\text { associated to age }>80 \text { years } \\
\text { or body weight }<60 \mathrm{~kg}\end{array}$ & Contraindicated \\
\hline
\end{tabular}

$\mathrm{CrCl}$, creatinine clearance; od, once daily; bid, twice daily. 
contraindicated. It would also be desirable to carry out these tests three times in the first year of treatment and every time there is the suspicion of deterioration in renal function. ${ }^{17,18,22-24}$ In this context, reference should be made to the fact that creatinine levels are not representative of renal function, especially in the elderly. In clinical practice, it is quite common to find elderly patients with near normal creatinine values while $\mathrm{CrCl}$ is impaired. The Cockroft Gault or the MDRD formulas for estimation of renal function should be a familiar tool for physicians in the era of DOACs.

\section{Drug and food interactions}

Vitamin $\mathrm{K}$ antagonists are limited by their multiple interactions with drugs, herbal products and food that contribute to their narrow therapeutic window. In contrast to VKAs, DOACs have limited drug interaction and are not influenced by food or herbal products. ${ }^{28}$ Drug interactions are limited to drugs interfering with P-glycoprotein (P-Gly) for dabigatran and with P-Gly and cytochrome P3A4 for the Factor Xa inhibitors. ${ }^{28}$ Table 4 summarizes the main drug interactions with DOACs and recommendations for dose adjustment.

The peak plasma concentration of dabigatran could be delayed by $2 \mathrm{~h}$ when administered with food. Therefore, it is preferrable to administrate the drug between meals. ${ }^{17,28}$

\section{Other situations at increased bleeding risk}

Many other clinical conditions encountered in real life other than those mentioned above could expose patients on DOACs to a risk of bleeding. The concomitant use of other antithrombotic agents (especially antiplatelet drugs), the use of non-steroidal anti-inflammatory drugs, the presence of congenital or acquired coagulation disorders (e.g. abnormalities in platelet count or function, gastrointestinal ulcerations, active or recent bleedings, especially if intracranial), recent biopsy, recent spinal, brain and ocular surgery, and bacterial endocarditis, all expose patients to a risk of bleeding. ${ }^{17,18,22-24}$ In these subjects, DOACs may be absolutely or relatively contraindicated and a close evaluation of the balance between thrombotic and bleeding risk should drive the choice of optimal treatment for the individual patient.

One of the main concerns with the use of concomitant drugs in patients treated with DOACs is related to antiplatelet molecules. In the RCTs on DOACS in patients with NVAF, around one-third of patients were taking acetylsalicylicacid (ASA). ${ }^{2-5}$ Despite the fact that the bleeding risk increases in patients taking DOACs plus ASA compared with patients taking DOACs alone, the safety profile remains favorable for the association DOACs/ASA over warfarin/ASA, especially with regards to intracranial bleedings. However, lower dose of dabigatran (110 mg bid) resulted safer when compared with higher dose (150 mg bid) in this context. ${ }^{31}$ Therefore, in patients needing contemporary treatment with dabigatran and ASA, the lower dose should be preferred. There is no evidence for dose adjustment of rivaroxaban and apixaban in the context of patients taking these drugs associated to ASA.

\section{Conclusions}

Use of the DOACs could certainly be advantageous and represent a true therapeutic revolution in the management of thromboembolic disease. However, many aspects of their management in real life clinical practice still remain unknown. It would, there-

Table 4. Drug interactions and dose adjustment for DOACs.

\begin{tabular}{|c|c|c|c|}
\hline \multicolumn{4}{|c|}{ Dabigatran } \\
\hline Caution but use possible at standard dose & $\begin{array}{l}\text { Caution } \\
\text { ce dose to } 110 \mathrm{mg} \text { bid }\end{array}$ & Not recommended & Contraindicated \\
\hline $\begin{array}{l}\text { Atorvastatin, diclofenac, pantoprazole, clopidogrel, } \\
\text { digoxin, amiodarone, quinidine, clarithromycin }\end{array}$ & Verapamil & $\begin{array}{c}\text { Dronedarone, } \\
\text { carbamazepine, rifampicin, } \\
\text { phenytoin, anti-retroviral drugs }\end{array}$ & $\begin{array}{l}\text { Azoles, tacrolimus, } \\
\text { cyclosporine }\end{array}$ \\
\hline \multicolumn{4}{|c|}{ Anti-Xa } \\
\hline $\begin{array}{r}\text { Caution but use possible at standard dose } \\
\text { The a } \\
\text { be re } \\
\text { of P-glyc }\end{array}$ & $\begin{array}{l}\text { Caution } \\
\text { icoagulant effect could } \\
\text { uced because inducers } \\
\text { orotein or cytochrome } 3 \mathrm{~A} 4\end{array}$ & $\begin{array}{c}\text { Caution } \\
\text { The anticoagulant effect could } \\
\text { be increased because inhibitors } \\
\text { of P-glycoprotein or cytochrome 3A4 }\end{array}$ & Contraindicated \\
\hline Digoxin, atorvastatin, midazolam & $\begin{array}{l}\text { apicin, phenobarbital, } \\
\text { toin, carbamazepine, } \\
\text { hypericum }\end{array}$ & $\begin{array}{c}\text { Fluconazole, erythromycin, } \\
\text { clarythromycin, amiodarone, } \\
\text { verapamil }\end{array}$ & $\begin{array}{l}\text { Azoles, } \\
\text { anti-retroviral } \\
\text { drugs }\end{array}$ \\
\hline
\end{tabular}


fore, be desirable, especially at this stage, to follow the practical recommendations derived from the inclusion and exclusion criteria used in phase III RCTs or suggested as expert opinions or evidence provided by continuous reports in the literature.

Adjusted doses of DOACS should be carefully considered in special situations such as renal and liver impairment, advanced age, extreme low body weight, high bleeding risk patients, and in patients taking drugs that interact with P-Gly and/or cytochrome P3A4.

\section{References}

1. Gómez-Outes A, Terleira-Fernández AI, Suárez-Gea ML, et al. Rivaroxaban, or apixaban versus enoxaparin for thromboprophylaxis after total hip or knee replacement: systematic review, meta-analysis, and indirect treatment comparisons. BMJ 2012;344:e3675.

2. Connolly SJ, Ezekowitz MD, Yusuf S, et al. Dabigatran versus warfarin in patients with atrial fibrillation. N Eng J Med 2009;361:1139-51.

3. Connolly SJ, Ezekowitz MD, Yusuf S, et al. Newly identified events in the RE-LY trial. N Eng J Med 2010;363: 1875-6.

4. Patel MR, Mahaffey KW, Garg J, et al. Rivaroxaban versus warfarin in nonvalvular atrial fibrillation. N Engl J Med 2011;365:883-91.

5. Granger CB, Alexander JH, McMurray JJ, et al. Apixaban versus warfarin in patients with atrial fibrillation. $\mathrm{N}$ Engl J Med 2011;365:981-92.

6. Connolly SJ, Eikelboom J, Joyner C, et al. Apixaban in patients with atrial fibrillation. N Eng J Med 2011;364: 806-17.

7. Gibson CM, Mega JL, Burton P, et al. Rationale and design of the Anti-Xa therapy to lower cardiovascular events in addition to standard therapy in subjects with acute coronary syndrome-thrombolysis in myocardial infarction 51 (ATLA-ACS 2 TIMI 51) trial: a randomized, doubleblind, placebo-controlled study to evaluate the efficacy and safety of rivaroxaban in subjects with acute coronary syndrome. Am Heart J 2011;161:e6.

8. The EINSTEIN Investigators. Oral rivaroxaban for symptomatic venous thromboembolism. N Eng J Med 2010;263:2499-510.

9. The EINSTEIN Investigators. Oral rivaroxaban for the treatment of sympromatic pulmonary embolism. N Eng J Med 2012;366:1287-97.

10. Schulman S, Kearon C, Kakkar AK, et al. Extended use of dabigatran, warfarin, or placebo in venous thromboembolism. N Engl J Med 2013;368:709-18.

11. Southworth MR, Reichman ME, Unger EF. Dabigatran and postmarketing reports of bleeding. N Eng J Med 2013. [Epub ahead of print].

12. Beyer-Westendorf J, Lützner J, Donath L, et al. Efficacy and safety of thromboprophylaxis with low-molecularweight heparin or rivaroxaban in hip and knee replacement surgery: findings from the ORTHO-TEP registry. Thromb Haemost 2013;109:154-63.

13. Beyer-Westendorf J, Lützner J, Donath L, et al. Efficacy and safety of rivaroxaban or fondaparinux thromboprophylaxis in major orthopedic surgery: findings from the ORTHO-TEP registry. J Thromb Haemost 2012;10: 2045-52.

14. Turpie AG, Schmidt AC, Kreutz R, et al. Rationale and design of XAMOS: noninterventional study of rivaroxaban for prophylaxis of venous thromboembolism after major hip and knee surgery. Vasc Health Risk Manag 2012;8:363-70.

15. Turpie AG, Schmidt A, Lassen MR, et al. Rivaroxaban for thromboprophylaxis after total hip or kneereplacement Surgery: Comparison of Outcomes of the XAMOS and RECORD Studies. Blood (ASH Annual Meeting Abstracts) 2012;120:Abstract 1160 .

16. Rosencher N, Frostick S, Feuring M, et al. Real-World Study of Dabigatran Etexilate for Thromboprophylaxis in Over 5000 Hip or Knee Replacement Patients: Favourable Safety Profile in Subgroups with Different BMI, Renal Function and Age. Blood (ASH Annual Meeting Abstracts) 2012;120:Abstract 1160 .

17. Huisman MV, Lip GYH, Diener HC, et al. Dabigatran etexilate for stroke prevention in patients with atrial fibrillation: resolving uncertainties in routine practice. Thromb Haemost 2012;107:838-47.

18. Camm AJ, Lip GY, De Caterina R., et al. 2012 Focused update of the ESC guidelines for the management of atrial fibrillation. An update of 2010 ESC guidelines for the management of atrial fibrillation. Eur Heart $\mathrm{J}$ 2012;33:2719-47.

19. Furie KL, Goldstein LB, Albers GW et al. Oral antithrombotic agents for the prevention of stroke in nonvalvular atrial fibrillation: a science advisory for healthcare professionals from the American Heart Association/American Stroke Association. Stroke 2012;43: 3442-53.

20. LaHaye SA, Gibbens SL, Ball DG, et al. A clinical decision aid for the selection of antithrombotic therapy for the prevention of stroke due to atrial fibrillation. Eur Heart J 2012;33:2163-71.

21. Schulman S, Kearon C, Kakkar AK, et al. Dabigatran versus warfarin in the treatment of acute venous thromboembolism. N Engl J Med 2009;361:2342-52.

22. Turpie AGG, Kreutz R, Llau J, et al. Management consensus guidance for the use of rivaroxaban -an oral, direct factor Xa inhibitor. Thromb Haemost 2012;108: 876-86.

23. Palareti G, Ageno W, Ferrari A, et al. Clinical management of rivaroxaban-treated patients. Expert Opin Pharmacother 2013;14:655-67.

24. European Commission. RCP apixaban; 2011. Available from: http:/ec.europa.eu/health/documents/communityregister/2011/20110518102349/anx_102349_it.pdf

25. Agnelli G, Buller HR, Cohen A, et al.; the AMPLIFY Investigators. Oral Apixaban for the Treatment of Acute Venous Thromboembolism. N Engl J Med 2013;369: 799-808.

26. European Medicines Agency. Available from: http:// www.ema.europa.eu/docs/en_GB/document_library/ EPAR_-_Assessment_Report_-_Variation/human /000829/WC500110875.pdf

27. Eikelboom JW, Wallentin L, Connolly SJ, et al. Risk of bleeding with 2 doses of dabigatran compared with warfarin in older and younger patients with atrial fibrilla- 
tion: an analysis of the randomized evaluation of longterm anticoagulant therapy (RE-LY) trial. Circulation 2011;123:2363-72.

28. Weitz J, Eikelboom JW, Samama MM. New antithrombotic drugs: Antithrombotic Therapy and Prevention of Thrombosis, 9th ed: American College of Chest Physicians Evidence-Based Clinical Practice Guidelines. Chest 2012;141:e120S-e151S.

29. Fox KA, Piccini JP, Wojdyla D, et al. Prevention of stroke and systemic embolism with rivaroxaban compared with warfarin in patients with non-valvular atrial fibrillation and moderate renal impairment. Eur Heart J 2011;32:2387-94.

30. Harper P, Young L, Merriman E. Bleeding risk with dabigatran in the frail elderly. N Engl J Med 2012;366: 864-6.

31. Dans AL, Connolly SJ, Wallentin L, et al. Concomitant use of antiplatelet therapy with dabigatran or warfarin in the Randomized Evaluation of Long-Term Anticoagulation Therapy (RE-LY) trial. Circulation 2013; 127 : 634-40. 